This is the post print version of the article, which has been published in Journal of studies in international education . 2018, 22 (4), 353-368. http://dx.doi.org/10.1177/1028315318773141.

\title{
Re-framing education export from the perspective of intellectual capital transfer
}

\author{
Authors: Antti Lönnqvist, Harri Laihonen, Yuzhuo Cai and Kirsi Hasanen
}

\section{Introduction}

It is well known that a nation's knowledge-related resources, i.e. national intellectual capital, have a significant impact on the development and prosperity of the country (Lin \& Edvinsson, 2011; Ståhle \& Bounfour, 2008). Therefore, investing in national intellectual capital can be considered a justified development policy (Käpylä et al., 2012). International collaboration in the field of higher education is becoming a beneficial way for developing countries to acquire human capital from more developed countries (Bennell \& Pearce, 2008). Through collaboration, the processes and practices of a high-standard education can be transferred to developing countries in order to create the capacity and possibilities for intellectual capital renewal. Moreover, this activity can be a business opportunity, and it can be motivating from an academic or societal impact perspective (Schatz, 2015). Furthermore, export activity can help countries with more advanced higher education systems to identify knowledge-related resources and to explicate the prevailing education processes and practices.

Although there is already a relatively long tradition of education export, it can still be considered a growing phenomenon (Cai et al., 2012). For example, Finland has only during recent decades started to promote education export as a means to leverage the country's strong human capital base and to search for opportunities to become a more active player in the higher education market (Cai et al., 2013; Schatz, 2016).

For many universities, education export is a new type of activity, in contrast to the more traditional non-profit forms of academic internationalization (e.g. student and staff mobility or cross-border research and education projects). Prior research has shown that there are many challenges in carrying out education export activities (Cai et al., 2012; Knight, 2013; Naidoo, 2010). Some of them are quite pragmatic; as education export is a new activity for many universities, they simply lack the necessary skills and routines, such as those related to marketing (Naidoo, 2010). More fundamental questions have also been raised. For example, in an article analyzing the trends of the internationalization of higher education, Knight (2013, p. 88) stressed that 'an increased emphasis on the "buying and selling" of education across borders will affect the nature and priority given to academic, social and cultural purposes of non-profit international 
education'. Another related challenge indicated by Knight is the decoupling of the universities' demand for the commercialization of education and the willingness of academics to commit to developing relevant activities. This may relate to a potential conflict between the values of academics - who are used to a non-profit logic in international academic collaboration - and those related to a more commercial orientation. Based on the experience gathered in Australia, education export strategy often fails without concomitant academic involvement and participation (Poole \& Ewan, 2010).

The challenges concerning international education mentioned by, for example, Knight (2013) and Naidoo (2010), are also reflected in the discussion about recent education export efforts in Finland. For instance, Schatz (2016) criticizes the Finnish education export strategy for being too vague and because its underlying values cannot easily be adopted by many of the academics expected to be key actors in the export arena. This very recent observation supports previous analysis of the readiness of Finnish education export by Cai, Hölttä and Kivistö (2012), which was based on the education export strategy launched by the Finnish government in 2009 (Finnish Ministry of Education and Culture, 2009).

In order to more clearly comprehend education export and the related challenges - and to identify solutions for these challenges - in this paper we examine education export from the perspective of intellectual capital. In other words, we conceptualize education export as an activity aimed at transferring intellectual capital as a two-way process benefiting both ends of the collaboration.

There is no prior research examining education export from the intellectual capital perspective. It can be assumed that depicting the concept of intellectual capital as a premise will be useful in forming a better understanding of the various aspects of education export. First, it can help the exporting institution to identify in a more fine-gained manner the various knowledge-related resources needed for successful education export activity. This could have managerial relevance in terms of identifying areas that require development actions. Second, if we are able to recognize the various intellectual capital-related benefits of education export we may be better equipped to solve the value conflict mentioned above. In other words, if we are capable of reframing the value of education export (not only as having a monetary value for the exporting institution but also as producing many intangible benefits for several stakeholders), it may encourage and motivate academics to participate in these activities. Consequently, in this paper we ask: how can intellectual capital transfer be used as an analytical tool to gain an understanding of the nature and challenges of education export? 


\title{
2 Integrating the research fields of intellectual capital and education export
}

\author{
2.1 Intellectual capital \\ Intellectual capital is a concept that refers to various immaterial sources of value creation (Lev, \\ 2001; Lönnqvist et al., 2009; Schiuma et al., 2007). Commonly, the concept is applied at \\ organizational level and examined from three main perspectives. Human capital consists of issues \\ related to individuals' capabilities, expertise, education and past experiences; structural capital \\ consists of knowledge-based resources embedded in the organization's culture, structure, processes \\ and systems; and relational capital consists of the relationships the organization has with its \\ stakeholders, including the organization's image and product brands (Sveiby, 1997; Seetharaman et
} al., 2002).

Intellectual capital is valuable, although the exact value is difficult to measure as it depends on the context and the manner of its utilization. Thus, in addition to discussing how much and which kinds of intellectual capital there are or should be, it is important to understand how intellectual capital can be transformed into value (Laihonen \& Lönnqvist, 2010).

The concept of intellectual capital is also used at the level of cities, regions and nations (Carrillo et al., 2014; Stam \& Andriessen, 2009). According to Käpylä et al. (2012), national intellectual capital consists of, for example:

- all individuals' knowledge, education, attitudes, values

- $\quad$ social knowledge, networks, culture and trust within the society

- international relations and cooperation, image of the country internationally

- academic infrastructure, innovation system, governmental and political practices

Prior research suggests there is a connection between high levels of national intellectual capital and the economic performance of the nation (Lin \& Edvinsson, 2011; Ståhle \& Bounfour, 2008). Generally, higher levels of intellectual capital are likely to lead to good economic performance; however, the relationships are complex and context-dependent (Käpylä et al., 2012). Nevertheless, in the pursuit of development, nations (and cities, regions, public organizations and companies) are investing in intellectual capital. The current literature on national intellectual capital is tilted towards studies that develop indicators and benchmark countries' intellectual capital, while fewer studies discuss how national intellectual capital could be transferred or developed. Thus, this paper 
contributes to the intellectual capital research field by examining education export as a form of national intellectual capital transfer and as a process benefitting both parties involved.

\subsection{Education export}

Education export is an aspect of the internationalization of higher education (Bennell \& Pearce, 2003). According to Schatz (2015, p. 330), it can be defined narrowly as 'an intentional business transaction concerning education practices, service and materials from one country to another', or broadly as 'any conscious or unconscious form of education distribution'. As developing countries have begun to acknowledge that an increase in the education level of the population is likely to lead to economic development, the demand for education export has started to grow (Lenn, 2000). For highly populated countries, education export serves as a means of accessing education, particularly when local institutions cannot meet the demand (Altbach \& Knight, 2007; Bannier, 2016; Healey \& Michael, 2015).

Education export can take many forms. A traditional form is to collect student fees from international students; another typical way to export education is to provide commissioned programmes abroad. In the case analyzed in this paper, the students stay in their home country while the faculty of the provider university travels to deliver the education. According to Lenn (2000), other examples of education export include universities setting up branch campuses abroad, franchised degree programmes and distance programmes using online techniques.

For the leading countries, such as Australia, the UK and the USA, education export is a multibillion dollar business annually

(Bennell \& Pearce, 2003; Lenn, 2000; Naidoo, 2010). Due to the leading countries' success, many other countries are trying to follow their lead. From the provider's perspective, transforming a strong national knowledge base into a source of export income is a key motivation of education export at the national level (Cai et al., 2013). Another motivating factor may be the possibility to have a positive impact on the world (e.g. on the environment, health or social wellbeing) through education export (Schatz, 2015). For the universities providing the education, export activities may be a way to increase the institution's reputation and funding. Simultaneously, for the customer universities, foreign programmes offer cooperation opportunities with foreign partners and a crosscultural perspective for their students. Collaboration with a foreign university may also increase understanding of international education standards and practices (like curriculum management and delivery) in order to develop better-quality practices. For individuals (the customers) who are unable or unwilling to travel abroad to study, a highly respected international university degree becomes accessible and helps them differentiate themselves in the job market (Bennell \& Pearce, 2003; Tran, 2014). 
Education export may be a promising opportunity for all parties involved, but there are also some challenges to address. First, there are ethical concerns. International academic mobility favors the well-developed education systems and, thus, may compound existing inequalities (Altbach \& Knight, 2007; Tran, 2014; Bannier, 2016). From this perspective, education export equates to developed countries providing education to developing countries. While doing this, developed counties also spread their cultural models and practices, which can be viewed as a questionable practice. On the other hand, education export can be considered an ethical undertaking, as it educates global citizens by sharing successful education recipes for everyone's benefit (Schatz, 2015). Second, many issues relating to resources and practices affect the success of export programmes. Since the basic mission of universities is research and education, they may lack the required market orientation and, as a result, might not be equipped for export activities (Naidoo, 2010). Moreover, not all academics are interested in commercial education activities, given that the academic tradition is often oriented towards non-profit forms of value creation (Knight, 2013) and altruistic motives enhancing the welfare of others (cf. Wilkins and Urbanovic, 2014).

Practical challenges related to running export programmes include the management of students' language proficiency, the students' access to library services and other important resources, programme governance, the availability of skilled teachers and budget issues (Lenn, 2000). Other concerns reported in previous literature include the lack of experience and knowledge in marketing, insufficient motivation and commitment and the lack of coordination in exporting education (Cai et al., 2012). Thus, education export is not a straightforward business.

\subsection{Education export from the intellectual capital perspective}

In this paper, we examine education export as a means to transfer national intellectual capital. In this setting, a provider country and organization (e.g. a university or a company) considers itself as possessing potentially valuable intellectual capital that could be put to use and developed into a revenue stream through education export activities. As discussed, there are also altruistic motives present but the establishment of new activities often requires an initial investment. Furthermore, the continuity of these activities can only be guaranteed by a continuous and steady revenue stream. Thus, despite the underlying altruistic motives the providing institution seldom has a possibility to ignore the financial aspects of education export. On the other side, there is a customer (e.g. an institution or an individual) that considers education export as a useful way to acquire some aspects of intellectual capital, especially elements of human capital. In order to elaborate this issue, the role of intellectual capital in education export will be examined first from the customer's perspective and then from the provider's perspective. 
Customer perspective: acquiring intellectual capital through education export. The customer's societal or organizational development goals and the status of their current intellectual capital determine the kinds of intellectual capital required in a given situation. For example, a need for a certain kind of human capital typically arises because there is a lack of expertise considered important for achieving the chosen economic, societal or environmental development goals.

On the customer side, there are actors on different levels. First, there is the individual person - a student - who aims to develop his/her human capital. The motivation here is to acquire capabilities and a highly respected university degree to facilitate career development nationally or internationally. Second, there may be a local university or some other organization operating as a partner in the education programme. For such a partner institution, the export collaboration may provide the means to strengthen research and teaching capabilities and practices to boost its reputation and help attract students. Third, from a national (or regional) perspective, export programmes are expected to produce workers qualified to serve the needs of the labor market and to develop the country's own infrastructure related to, for example, education, innovation and governance. It can be assumed that other forms of national intellectual capital may be developed, and later the societal development goals achieved through utilizing the newly developed human capital.

Consequently, the required types of intellectual capital depend on the goals set and on the current level of the relevant intellectual capital. Moreover, the types of intellectual capital developed through education export activities vary depending on the level of examination. Authors' conceptualization of these levels is illustrated in Figure 1 and analyzed further in section 3.2.

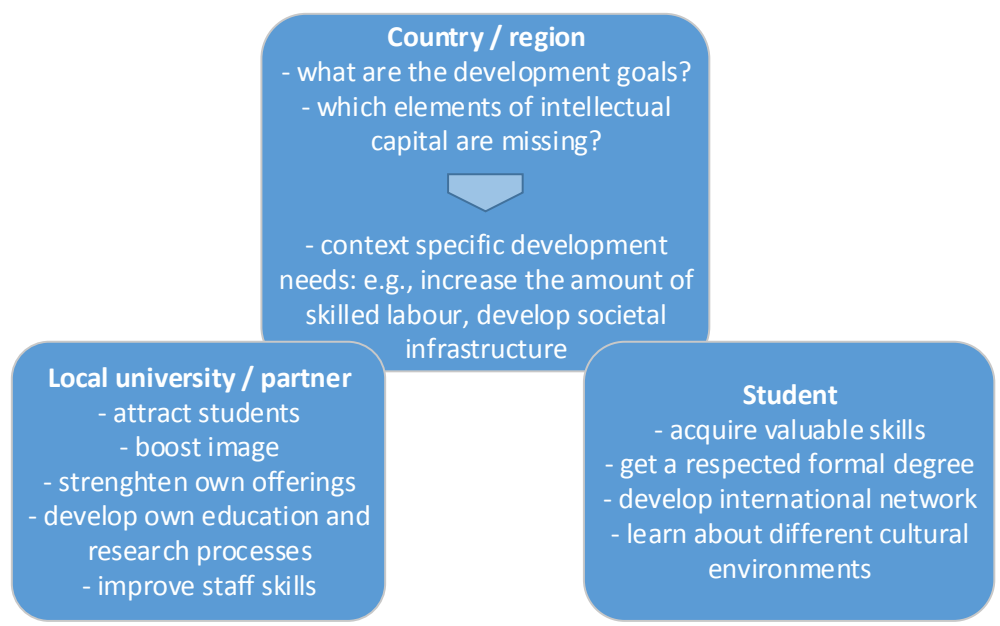

Figure 1. Intellectual capital-related customer needs for education export. 
Investing in education involves risks and there are many things that can go wrong in an export project. One noteworthy issue is student selection; for example, if the students' academic skills (including language skills) are not adequate to keep up with the education on offer then the project may be doomed to failure. Another risk is that even if the students are able to finish the programme successfully, it may not automatically lead to the desired outcomes in terms of societal goals. This relates to the way in which the new expertise is utilized in the labor market. Thus, in line with Naidoo's (2010) 'export readiness' concept, it might be worth considering the 'import readiness' in each case setting, i.e. whether the students have the adequate expertise (in terms of substance and language) and whether there are mechanisms in place to absorb and leverage these capabilities in the labor market.

Provider perspective: transferring intellectual capital through education export. Table 1 lists examples of intellectual capital that are likely to be necessary preconditions or important drivers of a successful export project. These will be further analyzed in empirical section 3.3. First, the export organization is required to possess human capital that fits the export purposes. There is a need for highly skilled academics, but research-oriented academic staff are not automatically motivated by export activities. Thus, there is a demand for staff members interested in working with international students and in international locations. In addition, skills related to, for example, marketing and understanding the local context are required. Second, elements related to structural capital are also necessary. For example, education products, i.e. degree programmes or short courses, should be scalable and appealing from the customer's perspective. Third, the export organization should leverage its (or its home country's) positive education image and brand. For example, Finnish export organizations aim to capitalize on Finland's good reputation in PISA studies (Schatz, 2015); in other cases, the image might be based on a world-class research reputation. In addition, successful export projects benefit from good partnerships that help in student recruitment, for example.

Key elements of an education export organization's intellectual capital

Table 1

\begin{tabular}{|l|l|l|}
\hline Human capital & Structural capital & Relational capital \\
\hline - skilled teachers & - education products & - image and brand of the \\
- teachers' motivation & - pedagogic and ICT tools for & country/university \\
towards education export - & delivery & -knowledge of customer \\
sales and marketing skills - & - processes for governing the & needs \\
knowledge of the local & programmes & -partner organizations (e.g. \\
context & & for marketing) \\
\hline
\end{tabular}


There are risks concerning the export provider as well; in the early stages of export activities in particular, there may be gaps in any of the elements listed in Table 1. For example, if the pedagogic approaches are not suitable for the local context, this can lead to additional workloads for the teachers and increased costs for the organization. Education export can be regarded as a positive activity that increases an organization's visibility and strengthens its image internationally. However, problems in the export projects (e.g. cases of plagiarism or other unethical behavior) could also have a negative effect on the image. Other potential risks include, for example, the misuse of the organization's immaterial property rights and potential legal problems with contractual partners.

\section{Case study}

\subsection{Research setting and methods}

The Faculty of Management at the University of Tampere (UTA) has carried out various education export projects in Vietnam since 2011; it has granted approximately 40 master's degrees in Public Policy and Financial Management to students of the National Academy of Public Administration (NAPA). All of the students work for the Vietnamese government in different administrative roles. In addition, 21 MPA (equivalent to MBA) degrees were granted in NAPA in 2016. Furthermore, resulting from cooperation with the University of Economics, Ho Chi Minh City (UEH), 21 Vietnamese master's degree students graduated in 2016 from the Public Administration programme. Currently, about 60 students are carrying out their master's degree studies in the joint master's degree programmes with NAPA.

In this paper, we apply a qualitative case study approach (Gummesson, 2000; Voss et al., 2002; Yin, 2009) by analyzing the education export activities of UTA in Vietnam as empirical data. Thus, the service provider is a Finnish university (UTA), whereas Vietnam as a nation, Vietnamese education institutions and Vietnamese students are the customers. The data was gathered through an action research process during the period 2014-2017. Thus, the empirical analysis benefits from the experiences of the authors, who have participated in UTA's education export activities in various roles. Marketing and sellingeducation services, negotiating with the customer universities regarding the curriculum content, and teaching and interacting with students in the classrooms have provided the authors with an in-depth view of the export practices. Furthermore, the authors have 
participated in ministry-level discussions concerning, for example, the national-level needs and the funding of these programmes. In practice, the empirical data consists of dozens if not hundreds of discussions and emails between the actors participating in the planning, executing and evaluation of education export activities. In addition, this information is complemented with the authors' personal observations and secondary data consisting of various strategy and policy documents of both countries and the universities at both ends of the partnership. Thus, by collecting data from different sources to be analyzed by authors with different perspectives, elements from triangulation strategy were applied to construct comprehensive understanding and description of the phenomenon.

The empirical data is analyzed from the perspective of the theoretical framework on intellectual capital in education export constructed by the authors in section 2.3. After formulating the conceptual framework, a more detailed analysis of the data was conducted by the authors to illustrate the applicability of this conceptualization. As a result, the two-fold analysis identifies and explicates the elements of intellectual capital transfer from the viewpoints of a customer and providing institution. The intangible aspects that drive customer motivation for engaging to intellectual capital transfer (see Figure 1) are analyzed in section 3.2, while the provider's perspective (see Table 1) is further elaborated in section 3.3.

\subsection{Customer perspective}

National-level demand for education export. Over the past decade, Vietnam has experienced significant changes resulting from its transition from a centrally planned to a market-oriented economy. Vietnam reached the status of a lower middle-income country in 2010, and it has ambitiously determined to become a modern industrial country by 2020 . However, as noted by the Country Strategy for Development Cooperation with Vietnam 2013-2016 (Ministry for Foreign Affairs of Finland, 2013), vital to attaining the goal will be the level of success in building good governance, increasing respect for human rights and ensuring inclusiveness of growth.

Despite some significant achievements in terms of public administration reform in Vietnam, the current system remains heavily influenced by the former centralized and bureaucratic management mechanisms, and has difficulties responding adequately to the requirements of an open market economy. As part of the ongoing change, a thorough transformation of the higher education system is also needed. In terms of numbers, Vietnam's higher education system has grown dramatically over recent decades. Since 1995, the number of Vietnamese universities has increased, and reached 234 universities in 2012. Consequently, it has been argued that the demand for higher education cannot be met solely by the Vietnamese education system. (Clark, 2014). 
University-level demand for international education partners. In addition to capacity problems, a shortage of qualified teachers poses a problem for the Vietnamese education system and individual education institutions (Clark, 2014). This lack of resources has led to the closure of many Vietnamese universities. Thus, Vietnamese universities are increasingly looking for private-sector support and foreign participation in education and training services.

In addition to this more general call for international collaboration, the Vietnamese context has special characteristics and requirements that generate interest in what Finland and UTA have to offer. The Finnish public administration and governance systems rank highly in all areas; indeed, the Finnish public administration is one of the most efficient in the world at attracting many developing countries. Furthermore, UTA, and especially the Faculty of Management, is a well established institution and the biggest and most important educator of public officials in Finland. Therefore, the customer requirements and the capabilities and resources of the service provider intersect well creating a compatible foundation for this collaboration.

The Vietnamese higher education system has also been criticized due to the centralized control and governance that hampers the quality of the education and the creativity of staff and students (Hayden \& Lam, 2007). Accordingly, Do and Ho (2011) have proposed an increase in the autonomy of higher education institutions in Vietnam. From the Finnish perspective, in which selfgovernment and innovativeness are valued, the authors anticipate that autonomy would increase the efficiency of universities by, for example, allowing for more effective human resources management practices.

Finally, Vietnamese universities have been characterized as lacking a research-oriented outlook, and are criticized for the relatively few peer-reviewed international journal publications compared to other developing countries (Vallely \& Wilkinson, 2008). A more research-oriented culture would improve staff capabilities, boost the image of the institutions and help to attract the most promising students. Here, the different aspects of intellectual capital interweave; collaboration with a wellestablished Western university enables a high-quality offering, which enhances the attractiveness of education not only for students but also for staff. This assumed positive cycle is expected to generate additional resources and lead to other benefits in various areas of the academic environment.

Students' perspective on education export. From an individual student's perspective, we assume that earning a Finnish master's degree is an inviting opportunity. Here, one of the driving forces to participate is surely the finding that currently nearly 50 per cent of Vietnamese students cannot find a job after graduating, which emphasizes the value of a degree from a distinguished international 
university. Arising out of this, the curriculum and the learning objectives of the programmes must be scrutinized carefully. Thus, learning outcomes are required to match the needs of local labor markets.

\subsection{Provider perspective}

Human capital. For a knowledge-intensive organization, like a higher education institution, human capital and especially the academic expertise of the personnel forms a critical asset. In UTA's case, the activities were started by pioneering academics who were interested in sharing their expertise in an international setting. On a general note, when the internationalization expands, more personnel need to participate, and running a master's degree programme also requires the support and commitment of the administration of the exporting institution.

Universities' sales and marketing skills are typically not very strong, especially in countries like Finland with a tradition of tuition-free university education; here, commercial activities, such as the productizing and pricing of education services, are unfamiliar. However, the most challenging aspect is the context-bound nature of our knowledge and teaching, which becomes visible in intellectual capital transfer. Public sector management practices differ considerably between Finland and Vietnam, making it impossible to apply Finnish practices directly to the Vietnamese context. Thus, contextual understanding and sensitivity becomes a prerequisite for education export. On the other hand, identifying the contextuality of human capital becomes beneficial for the provider's research and teaching practices.

Structural capital. In order to build successful and financially sustainable education programmes it is essential that these programmes are clearly defined as individual education products. In a highly competitive market, all the financial benefits are easily wasted in the tendering and negotiation processes if the programme curriculum is being iterated for a long period. It is not unusual for these processes to take months, and sometimes even years. Clearly defined processes ease the marketing, negotiating, planning and implementing of the programmes. It is also easier to find the appropriate resources and allocate time for teaching if the programme is clearly defined and builds on existing study modules. Scalability and the ability to repeat and remodel the same programme in different contexts are important both in terms of quality and efficiency.

The systematization of processes is a prerequisite for internal governance, pedagogic practices and in the use of information technology. It is also important to create clear rules for compensation practices and incentives for academics to participate. All of these factors call for strategic planning, and the exporting institution needs to be clear about the objectives of education export. While the education export is growing from a small-scale activity involving only a few academics into a 
strategic focus area, open communication and clear plans are required. To some extent, this calls for a cultural change, which is often a slow process.

Relational capital. As discussed in Section 2.3, it appears to be highly important that the university is able to benefit either from its own image and brand or that of its home country. Universities starting export activities must be able to stand out from the leading universities in the education markets.

Nowadays, a company called Finland University is responsible for marketing and selling the education services of three Finnish universities. The idea is that Finland University provides UTA with expert services related to marketing, drawing up contracts and dealing with financial transactions, allowing UTA and its personnel to focus on the academic content and the delivery of the programmes.

Moreover, successfully delivered programmes bring new projects and new customers. In this area, UTA has succeeded; there are already a third and fourth round of programmes running with NAPA in Vietnam.

\subsection{Discussion}

Based on the above, some lessons learned can be summarized. First, the earlier research concerning the motivational factors of the customer is largely supported by the empirical examination (e.g. Bennell \& Pearce, 2008; Schatz, 2015). However, the threefold categorization, i.e. country, university and the individual student, helped us to recognize more detailed nuances in customer's needs related to intellectual capital components.

At the country level, the focus is essentially on improving competitiveness, and the education system plays a critical role in this (cf. Lin \& Edvinsson, 2011; Ståhle \& Bounfour, 2008). Our case study illustrated how these nation-specific needs always relate to wider societal development goals, which may set some particular requirements (e.g. to improve public administration). These needs guide the selection of the international education partner. From the education institution's point of view, the export programme can provide access to assets that are either missing from the local institution or that increase their competitiveness (e.g. qualified staff and being branded as an international university). Moreover, intellectual capital transfer reaches beyond the mere content of the education programmes, as it is also about capacity building and transferring the academic culture and practices to both ends of the partnership. At the level of individual students, an international degree helps differentiate them in the job market.

Similarly, the findings related to the key knowledge resources required by the education provider correspond fairly well to prior research concerning the potential problems and success factors of 
education export (Cai et al., 2012; Lenn, 2000; Naidoo, 2010). However, it can be claimed that the classification of important knowledge resources provides a systematic and structured way to identify the important aspects of successful education export activity.

To summarize, in this study, intellectual capital was utilized as an analytical lens to provide a better view of the customer's knowledge-related needs and the provider's key knowledge resources that are required for a successful education delivery. Our findings show that education export is not only about transferring academic knowledge and skills. Instead, it is motivated by the customer's need to obtain various kinds of intellectual capital. Likewise, successful delivery requires many types of human, structural and relational capital in addition to the actual academic knowledge that is being exported. Understanding the customer's requirements more thoroughly is likely to be useful for developing offerings that match their actual needs. For example, where the customer has a great appreciation of the brand of an international degree, it makes sense to stress factors related to that in planning and executing the programme. Moreover, understanding the array of various intellectual capital elements required in a successful education export operation could help managers identify areas for improvement. In particular, the framework developed (Figure 1) provides a potential managerial tool for systematically identifying and evaluating the intellectual capital-related success factors of export delivery. It seems possible that the framework can be further developed into a measurement tool to monitor and guide the development of export activities.

\section{Conclusions}

This study aimed to explore how insights into cross-border intellectual capital transfer could be used as an analytical tool to gain an understanding of the nature of education export and the challenges associated with it, both in general and particularly in the case of Finnish universities. Although much potential exists in education export, there are many challenges to be overcome. This has been reported and analyzed in several studies internationally (e.g. Knight, 2013) and in the Finnish context (e.g. Cai et al., 2012; Cai \& Kivistö, 2013; Calugareanu, 2015; Hölttä, Pekkola \& Cai, 2009; Schatz, 2015, 2016).

The key contribution of this paper is the conceptual and empirical analysis of education export from the intellectual capital perspective. The findings show that intellectual capital is a useful concept for obtaining a more detailed perception of the different kinds of knowledge-based resources that are transferred through education export activities: a) which new knowledge-based resources do customers at different levels aim to acquire? b) which resources are needed by the education provider in order to run successful export activities? 
By identifying and assessing the required elements of intellectual capital, matching both the provider's and customer's sides, the intellectual capital perspective can help to define the expectations and goals of an export programme. In addition, it supports recognizing and evaluating the prevailing educational processes and practices, context-bound knowledge, development areas, associated risks and, ultimately, the impacts created, thus providing a new perspective for identifying important factors affecting the success and failure of export activities (cf. Cai et al., 2012; Lenn, 2000; Naidoo, 2010). The intellectual capital perspective has potential both as a scholarly analysis framework and as a managerial tool (e.g. by using Table 1 as a checklist for required capabilities and resources). Moreover, perceiving education export as intellectual capital transfer - and seeing the various intangible and mutual benefits - might help academics to overcome the potential value conflict (Knight, 2013). The enhancement of value compatibility between education export and the traditional internationalization of higher education can be crucial to successfully implementing education export strategies in Finland and elsewhere.

\section{References}

Altbach, P. \& Knight, J. (2007). The internationalization of higher education: Motivations and realities. Journal of Studies in International Education, 11(3/4), 290-305.

Bannier, B. (2016). Global trends in transnational education. International Journal of Information and Education Technology, 6(1), 80-84.

Bennell, P. \& Pearce, T. (2003). The internationalisation of higher education: Exporting education to developing and transitional economies. International Journal of Educational Development, 23(2), 215-232.

Cai, Y., Hölttä, S. \& Lindholm, N. (2013). Establishing sub-campuses in China: A Finnish perspective. Journal of Research in International Education, 12(2), 142-154.

| Cai, Y., Hölttä, S. \& Kivistö, J. (2012). Finnish higher education institutions as exporters of education-Are they ready? In S. Ahola \& D. M. Hoffman (Eds.), Higher education research in Finland: Emerging structures and contemporary issues (pp. 215-233). Jyväskylä: Finnish Institute for Higher Educational Research, University of Jyväskylä.

Cai, Y. \& Kivistö, J. (2013). Tuition fees for international students in Finland-Where to go from here? Journal of Studies in International Education, 17(1), 55-78. doi:10.1177/1028315311429001

Calugareanu, S. (2015). Institutional logics influencing the engagement of academic in internationalization at the School of Management, University of Tampere (Master's dissertation). University of Tampere, Tampere.

Carrillo, F. J., Yigitcanlar, T., Garcia, B. \& Lönnqvist, A. (2014). Knowledge and the city: Concepts, applications and trends of knowledge-based urban development. New York: Routledge Studies in Human Geography.

Do, H. T. \& Ho, P. T. M. (2011). Governance reform in higher education of Vietnam. Retrieved fromhttps://www.eduhk.hk/apclc/roundtable2011/paper/Phuong\%20Ho\%20Thanh\%20My\&Do $\% 20$ Huy\%20Thinh2.pdf 
Gummesson, E. (2000). Qualitative methods in management research (2nd ed.). Thousand Oaks, CA: Sage Publications.

Hayden M. \& Lam T. (2007). Institutional autonomy for higher education in Vietnam. Higher Education Research \& Development, 26(1), 73-85.

Healey, N. \& Michael, L. (2015). Towards a new framework for analysing transnational education. Higher Education Policy, 28, 369-391.

Hölttä, S., Pekkola, E. \& Cai, Y. (2009). Training Chinese administrative officials in Finland and its relevance to Finnish "China strategies". Tiedepolitiikka (Science Policy), 2009(3), 29-42.

Käpylä, J., Kujansivu, P. \& Lönnqvist, A. (2012). National intellectual capital performance: A strategic approach. Journal of Intellectual Capital, 13(3), 343-362.

Knight, J. (2013). The changing landscape of higher education internationalisation - For better or worse? Perspectives: Policy and Practice in Higher Education, 17(3), 84-90. doi:10.1080/13603108.2012.753957

Laihonen, H. \& Lönnqvist, A. (2010). Knowledge-based value creation: Grasping the intangibility of service operations in Finland. International Journal of Knowledge-Based Development, 1(4), $331-345$.

Lenn, M. (2000). Higher education and the global marketplace: A practical guide to sustaining quality. On the Horizon, 8(5), 7-10.

Lev, B. (2001). Intangibles. Management, measurement, and reporting. Washington, DC: Brookings Institution Press.

Lin, C.Y.-Y. \& Edvinsson, L. (2011). National intellectual capital: Comparison of 40 countries. New York, NY: Springer.

Lönnqvist, A., Kianto, A. \& Sillanpää, V. (2009). Using intellectual capital management for facilitating organizational change. Journal of Intellectual Capital, 10(4), 559-572.

Ministry of Education and Culture of Finland. (2009). Strategy for the internationalisation of higher education institutions in Finland 2009-2015. Helsinki: Finnish Ministry of Education. Retrieved from http://www.minedu.fi/export/sites/default/OPM/Julkaisut/2009/liitteet/opm23.pdf.

Ministry of Foreign Affairs of Finland. (2013). Country strategy for development cooperation with Vietnam 2013-2016. Retrieved from http://formin.finland.fi/public/default.aspx?contentid=274544\&contentlan=2\&culture=en-US

Naidoo, V. (2010). From ivory towers to international business: Are universities export ready in their recruitment of international students? Journal of Studies in International Education, 14(1), 5-28.

Schatz, M. (2015). Toward one of the leading education-based economies? Investigating aims, strategies, and practices of Finland's education export landscape. Journal of Studies in International Education, 19(4), 327-340.

Schatz, M. (2016). Engines without fuel? Empirical findings on Finnish higher education institutions as education exporters. Policy Futures in Education, 14(3), 392-408.

Schiuma, G., Ordóñez de Pablos, P. \& Spender, J. C. (2007). Intellectual capital and company’s value creation dynamics. International Journal of Learning and Intellectual Capital, 4(4), 331341.

Seetharaman, A., Sooria, H. \& Saravanan, A. S. (2002). Intellectual capital accounting and reporting in the knowledge economy. Journal of Intellectual Capital, 3(2), 128-148.

Ståhle, P. \& Bounfour, A. (2008). Understanding dynamics of intellectual capital of nations. Journal of Intellectual Capital, 9(2), 164-177. 
Stam, C. D. \& Andriessen, D. G. (2009). Intellectual capital of the European Union 2008: Measuring the Lisbon strategy for growth and jobs. Electronic Journal of Knowledge Management, 7(4), 489-500.

Sveiby, K-E. (1997). The new organizational wealth: Managing and measuring knowledge-based assets. San Francisco, CA: Berrett-Koehler.

Tran, T. T. (2014). Internationalization of higher education in Vietnam. Opportunities and challenges. VNU Journal of Science: Foreign Studies, 30(3), 61-69.

Vallely, T. J. \& Wilkinson, B. (2008). Vietnamese higher education: Crisis and response. Memorandum: Higher Education Task Force, Harvard Kennedy School.

Voss, C., Tsikriktsis, N. \& Frohlich, M. (2002). Case research in operations management. International Journal of Operations \& Production Management, 22(2), 195-219.

Wilkins, S. \& Urbanovic, J. (2014). English as the lingua franca in transnational higher education: motives and prospects of institutions that teach in language other than English. Journal of Studies in International Education, 18(5), 405-425.

Yin, R. K. (2009). Case study research - Design and methods. Thousand Oaks, CA: Sage. 